\title{
VII International Congress
}

\section{FINAL PLENARY SESSION}

19 NOVEMBER, 1958

10.20 a.m.

President: DR. Kitamura

Vice-President: DR. WADE

The President thanked all members of the Congress for their hard work and assiduous attendance.

"The Report on Classification is in your hands. Do you wish to have it read?" Accepted that it be considered without reading (by show of hands). "Is it accepted or rejected?" Accepted (by show of hands).

"Report on Therapy is in your hands." Voted by the assembly not be read. Dr. T. F. Davey read the few suggested changes. The assembly now voted to accept the Report.

Report on Bacteriology and Pathology. Dr. Muir suggested it should be accepted. Dr. Hanks read some corrections in punctuation and some other corrections. The assembly now voted to accept the Report.

Report on Immunology had already been read in the symposium. The assembly voted to accept the Report.

Report on Epidemiology and Control. Dr. Doull read out some changes and additions.

Dr. Azulay complained of the lack of time to consider the report, and pointed out on page 11 the remarks at bottom of page 11 were not in agreement with the summary in No. 6 on p. 14: also on page 1, in the 2nd para., he wanted 'the dispensary' replaced by 'outpatient'. These changes were accepted.

The assembly voted to accept the Report.

Report on Social Aspects. This was read in the symposium and there was no need to read it now.

Dr. Such SANChIz proposed an addition on social rehabilitation and that the next Congress should have a special committee on rehabilitation.

Mr. Jagadisan said it was more a matter for the Council of ILA and of future Congresses, and the secretariat of I.L.A. would take note of it.

The Report on Social Aspects was accepted by vote of the Assembly.

DR. WADE said there would have to be an editorial committee to edit the Reports which are now acts of the Congress on their acceptance. 'The Congress recommends' will now replace 'The Committee recommends'.

Dr. MuIR reported a cable from Mr. Perry Burgess "We send heartfelt greetings to all: 7th Congress will be outstandingly successful".

DR. MUIR proposed a return telegram, which was approved by acclamation of the Congress. 
Mr. A. Donald Miller spoke as follows:

"Mr. President, as we come to the end of this memorable Congress I am sure that every delegate is deeply conscious of the debt we owe to those who have made these days together so happy and so significant.

We have met in your beautiful and ancient land where the graces of courtesy and culture still shine amid the stresses and ardours of technical progress. We are grateful for the abundant hospitality we have received, and as we scatter to many parts of the world we shall take fragrant memories of you, our true friends.

The Congress has been notable in many ways. To those of us who remember earlier ones the progressive advances in hopefulness and authority have been evident. And this Congress, I believe, will be remembered for its clarity of thinking, its unity of spirit, and its humanity of outlook.

There are those, Mr. President, to whom, on behalf of the members of the Congress, it is my privilege to express our thanks, though there are many who have earned our gratitude who cannot be mentioned personally.

First, we express our deep appreciation of the gracious and active part taken by THEIR IMPERIAL Highnesses PRINCE AND PRINCESS TAKAMATSU. Their help has been a visible confirmation of that Imperial concern which has been so marked in the past.

And then we are grateful to:

The Minister of Health and Welfare,

THE Minister OF Foreign AfFairs,

The Governor of THE METROPOLIS OF TOKYO, and

The President of the National Council of Science

for the various and valuable parts they have played in facilitating the gathering and operation of this Congress with such easy efficiency.

We are greatly indebted to the Tofu Kyokal and its President Mr. Shibusawa, and to the Japanese Leprosy Association which has been associated with the Tofu Kyokai in sponsoring all arrangements for our reception.

Especially must I make reference to the Organizing CoMmitTEE members, under the honorary chairmanship of DR. MITSUDA. It has been one of our greatest honours to meet this veteran and distinguished doctor who for over sixty years has rendered such yeoman service in Leprosy work.

We are grateful also for the acting chairmanship of DR. KITAMURA; and it is difficult to express adequately our thanks for the selfeffacing, arduous, and skilful work of the Executive Secretary, our good friend DR. HAMANO.

A member of the Committee who has rendered invaluable help in more ways than we can realise is the CHIEF LiaIson OfFICER, International Affairs, Ministry of Health and Welfare, our familiar guide and counseller Mr. SAITA.

To those and the Members of Staff of Tofu Kyokai and the many VolunTARY HelPERS we offer our warm gratitude.

The visits that have been made by delegates to the NATIONAL LEPROSY RESEARCH INSTITUTE and TAMA ZENSHO-EN were greatly 
appreciated and we are grateful to DR. KOBAYASHI and DR. HAYASHI and their staffs.

The LADIES COMMITTEE has rendered a splendid service in gracious helpfulness and imaginative planning for the happiness of the wives of delegates. We are grateful to these, and for all the other arrangements made for our social entertainment.

Our most sincere thanks also goes to the INTERNATIONAL LEPROSY AsSOCIATION and its distinguished officers. The Association has been co-sponsor of the Congress and of indispensable help. I am sure I voice the feeling of us all when I pay tribute to the gallant and devoted service rendered for so many years by DR. WADE, its President. In between two Congresses the Journal which he edits with meticulous care holds us all together and conserves what would otherwise become ephemeral. And to DR. MUIR, the SecretaryTreasurer, we pay our homage for the selfless and dynamic work he has engaged in, not only for this Congress but in blazing a trail of new and natural life. The Deputy Secretary, DR. Ross INNES, has quietly carried all the exacting burden of detailed minute-to-minute work, and our gratitude to him is very real.

I must now mention very summarily other bodies or people to whom we are grateful:

The World Health Organisation, represented by Dr. Fang, Director of the Western Pacific Region in Manila, and DR. GAY PRIETO, recently appointed Head of the newly-created leprosy section of WHO in Geneva.

The INTER PRETERS, led by Mr. Simha of the Geneva headquarters and Mr. Schellenberg of the Western Pacific Region office, and helped by their friends in Tokyo.

The simultaneous translation has been of a very high order; and many of us have listened and watched with fascination Mr. Simha translating technical papers with consummate ease and literary grace.

And then Miss McGregor of the Manila office who flooded with manuscripts and requests, has with imperturbable charm dealt, together with her office staff, with the oceans of typing and duplication.

To all these we are most grateful.

The Council of the InTERnational Organization of Medical SCIENCE has materially assisted by a grant to ILA in its preparatory work and by help to enable research workers in nearby countries to attend.

We are all most grateful also to DR. Dharmendra, on whose shoulders fell a great deal of preparatory work of a most important character when it was expected the Congress would be held in India. The Organizing Committee greatly benefited by his work, enabling it to prepare for the Congress in Japan at such short notice.

The beautiful flowers sent by PATIENTS have kept us in constant remembrance of those whom we endeavour to serve in many lands. Our greetings go to them, and the assurance of our loving concern.

Mr. President, I request you to accept this inadequate recital of our thanks, and I would ask delegates assembled here to express their endorsement of them by standing, and by applause. 


\title{
VII International Congress \\ CLOSING CEREMONY
}

\author{
Mr. A. SaIta, presided \\ DR. HAMANO, supporting
}

Dr. HANKS spoke on some outstanding features of the Congress.

"Mr. Chairman, members and sponsors of the VII Congress I count it an unusual privilege to have been invited to say a few words in recognition of the accomplishments of the VII Congress. On all sides, there has been praise for the organization, the program and the hospitality.

The symposia were illuminating and helpful. These and other papers have helped us to appreciate the progress in general areas of knowledge and in specific investigations. To mention but a few of the highlights (I am sure I do not do justice):

It seems possible that a way has been opened to the study of leprosy infections in experimental animals.

We have seen evidence that rat leprosy bacilli have been induced to grow in cell cultures in vitro.

We have been shown repeatedly that histologic studies of sites of the lepromin test may demonstrate response of lymphocytes and epithelioid cells, even when Mitsuda reactions are doubtful or mild.

It is gratifying to learn that the physiologic basis of physical incapacities and deformities has been more adequately defined; also that the simplest of preventive measures often suffice.

In immunology we have seen clearer analyses of the varied causes of the positive Mitsuda reaction, and the way in which this state can be established.

Work in serology has shown a new specificity of reactions.

The subject of classification has been examined more critically and wisely than ever before.

It seems possible that differences of opinion arise from several causes:

1. The difficulty of compressing into a few words both a snap-shot of the more stable polar types and a moving picture of the evolutionary and transitional stages of the disease.

2. If a suggestion from the side lines is permissible, I would emphasise that biological phenomena tend to form a well known distribution curve.

Extremes or polar types occur least often, while intermediate stages occur most frequently.

Recognition of the extreme differences between $\mathrm{L}$ and $\mathrm{T}$ leprosy historically should attract first attention.

We have now progressed to a point where study and patience will be required to work through this middle ground and to designate the evolutionary and transitional phases of leprosy.

This goal might be accomplished by constant communication within a standing committee and if its members take opportunity to examine patients wherever Leprologists may meet in every country where a Congress may be held." 
"I could not close these remarks without paying tribute to all who worked and sacrificed to make this meeting possible. We are indebted especially to our Japanese colleagues for their untiring sacrifices and for the wonderful way in which they have collaborated with us."

Mr. SAITA translated a special message from their Imperial Highnesses Prince and Princess Takamatsu, likewise the Minister of Health and Welfare (of good wishes and farewell). These were received by acclamation.

Dr. T. F. DAveY reviewed Therapy, Epidemiology and Control, and Social Work, and said:

"Mr. Chairman, in reviewing those aspects of this Congress which have dealt with therapy, epidemiology, control, and social work, it is well to remind ourselves that the 6th International Congress was held too early in the suphone age for the full implications of the new era to be understood. During the intervening years, and now at this Congress we have come to realise that we are in fact living through a revolution in the history of leprosy, the extent of which is only penetrating into all those human relationships where leprosy all too often brought fear, hopelessness and degradation. This Congress has illumined the fundamental changes which are going on and are affecting us all in our approach to this disease.

The leprosy worker has now new equipment of great value. He has a cheap, simple, and relatively effective basic treatment, capable of the widest application. Alternatives are available when needed, and more may safely be predicted. We have a new understanding of deformity and a new responsibility in its prevention. We are no longer a small group working in almost a state of professional isolation. We now have the inestimable benefit of the experience and knowledge of colleagues in other fields, for example tuberculosis and immunology, to reinforce our efforts, and powerful organisations like WHO and UNICEF to advise us and give practical assistance in our work.

For the patient, an entirely new situation has arisen. Because his sickness is for practical purposes curable, and knowledge of it is spreading, it need no longer bring loss of dignity. He now knows he is a man like anyone else. He may be able to lead a normal life while taking treatment and continue in his employment.

If a period in a leprosarium is called for, it is but for a time, and can profitably be spent in learning useful occupations and gaining physical, mental, and spiritual adjustment. For him the advances of medicine and surgery can bring ease in reactive episodes and abolish established deformity, and when the time comes for him to leave, we acknowledge a continuing responsibility for him.

Among the general public prejudice dies hard, but here too fundamental change is occuring. Mass treatment campaigns are not only exposing the extent to which leprosy has penetrated in many localities, but by rendering less infective the many, rather than rendering non-infective the few, they are striking a powerful blow at $M$. leprae in its natural environment.

This shift in emphasis from the settlement to the local dispensary is one of the focal points in our thinking at this Congress. We have been reminded that the only sound basis for leprosy control is know- 
ledge, for with the discovery that leprosy is both preventable and curable, the disease is robbed of its peculiar aura and becomes but one disease among many.

Leprosy education is thus another focal point in our responsibility to the public. From it alone can develop the normal and humane attitude which will minimise the social trauma caused by the disease to the patient and his family, and gain their co-operation in such public health measures as may be necessary. Only then can we expect the early diagnosis and treatment which is fundamental to leprosy control, and the easy rehabilitation which is the right of every patient.

We have in addition been guided in the technique of sound epidemiological observation, and heard the call for more integration between leprosy work and other health and social services.

As Mr. Jagadisan put it, the outlook on leprosy is brightening, and we who have shared in this Congress have witnessed that at first hand, for there has been a new unity among us. Enthusiasts we may be, but in pooling our experience and our problems we have both become wiser and gained in humility. If science can be married to sentiment, Mr. Follereau's motto may yet be realised, love may indeed conquer, the walls may indeed fall.

DR. HAmano expressed his pleasure and that of his colleagues of the kind words of appreciation.

He was grateful for the help of Dr. Wade, Dr. Muir and Dr. Ross Innes, also the simultaneous translators and especially for the help of Mr. Saita and all his colleagues in Japan. "I give you a greeting from all the patients in Japan who wish for an early eradication of leprosy in the world".

At 11.40 a.m. Mr. Saita declared the Congress closed. 